\title{
Porphyrin based metal-organic frameworks with record sensitivity in optical oxygen sensing
}

\author{
Tobias Burger, ${ }^{1}$ Christian Winkler, ${ }^{2}$ Irene Dalfen, ${ }^{1}$ Christian Slugovc, ${ }^{3, *}$ \\ Sergey M. Borisov ${ }^{1, *}$ \\ ${ }^{1}$ Graz University of Technology, Institute of Analytical Chemistry and Food Chemistry; Stremayrgasse 9; \\ 8010 Graz; Austria \\ ${ }^{2}$ Graz University of Technology, Institute of Solid State Physics; Petersgasse 16; 8010 Graz; Austria \\ ${ }^{3}$ Graz University of Technology, Institute of Institute for Chemistry and Technology of Materials;
} Stremayrgasse 9; 8010 Graz; Austria

\begin{abstract}
The optical oxygen sensing capabilities of the porphyrin-based metal-organic frameworks, PCN-224, $\mathrm{Pt}(\mathrm{II}) \mathrm{PCN}-224$ and $\mathrm{Pd}(\mathrm{II}) \mathrm{PCN}-224$ were investigated. The bimolecular quenching constants $\left(\mathrm{k}_{\mathrm{q}}\right)$ of 37000 (PCN-224), 6700 (Pd(II)PCN-224) and $3900 \mathrm{~Pa}^{-1} \mathrm{~s}^{-1}$ (Pt(II)PCN-224) were found and reveal an exceptionally high oxygen-permeability for these materials. A fast gas transport within the network, large pore sizes, electronic and spatial isolation of the porphyrin indicator in the framework are held responsible for the unprecedentedly high $\mathrm{k}_{\mathrm{q}}$ values. PCN-224 shows $6.7 \mathrm{~ns}$ fluorescence lifetime and the fluorescence in air is quenched by 4.2 -fold. The metal-organic frameworks based on phosphorescent $\mathrm{Pt}(\mathrm{II})$ and $\mathrm{Pd}(\mathrm{II})$ porphyrins possess significantly longer decay times of 18.6 and $390 \mu \mathrm{s}$, respectively, and are suited to detect oxygen in trace and ultra-trace ranges with limits of detection of 1 and $0.015 \mathrm{~Pa}$, respectively.

Apart from free-standing crystals, also metal-organic frameworks supported on different fibrous substrates (poly(acrylonitrile) nanofibers, glass fibres), and flat substrates (TLC silica-gel, poly(amide) filter) were prepared in order to provide oxygen sensor materials of practical use. Electrospun and thermally treated poly(acrylonitrile) nanofibers were proven to be particularly favourable and the resulting composite material exhibited the same sensitivity as the free crystals. All sensing materials show reversible cross-talk to humidity at levels up to $53 \%$ relative humidity but demonstrate a drastic decrease of oxygen sensitivity at high humidity levels and when exposed to water.
\end{abstract}
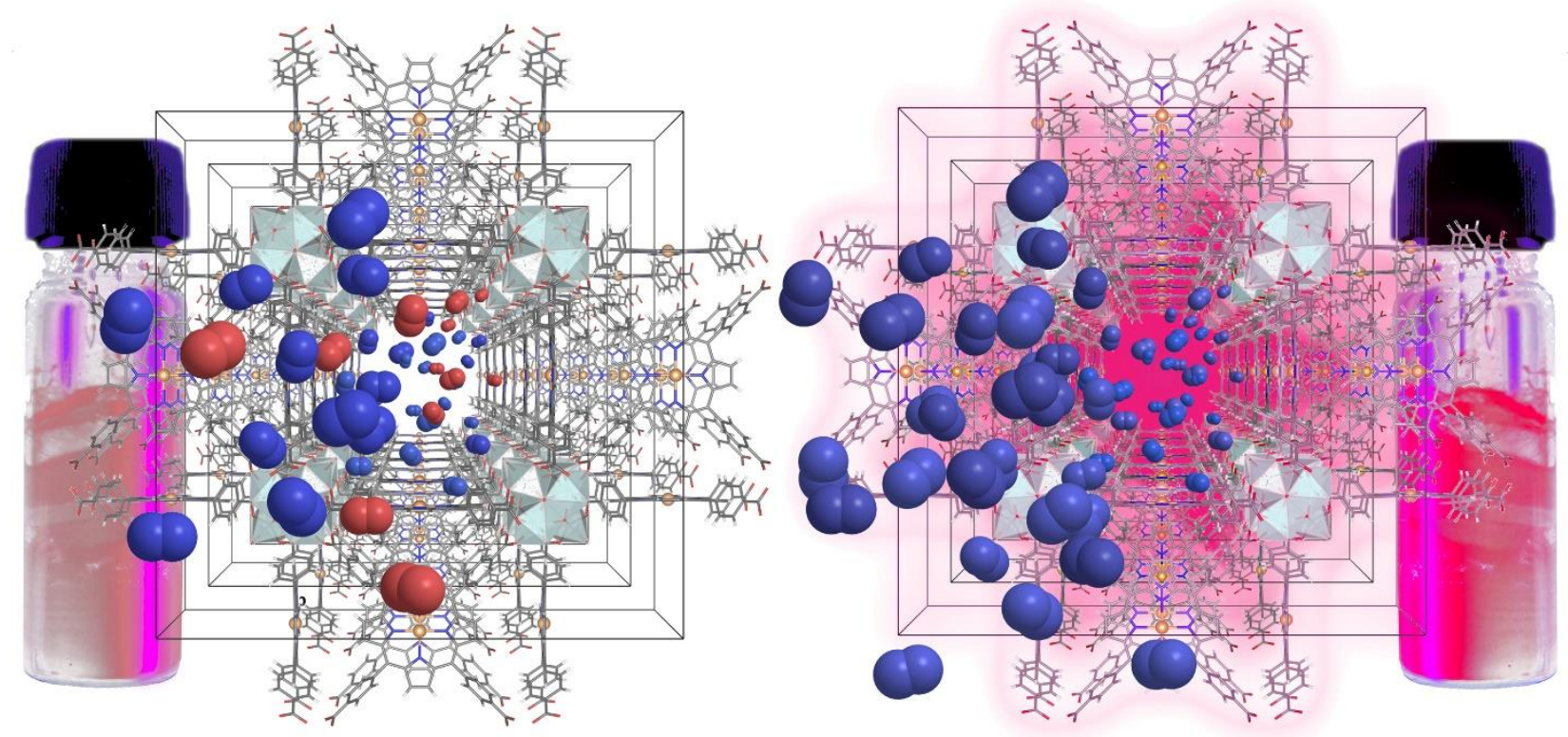

Keywords: metal-organic framework; luminescence, platinum; palladium; porphyrin 


\section{Introduction}

Widely applied optical oxygen sensors rely on quenching of the luminescence of an indicator by molecular oxygen. ${ }^{1}$ Although the state-of-the-art sensors are well suited for most applications and some are commercially available, there is still considerable interest for further improvements in applications like trace or ultra-trace sensing ${ }^{2}$ or measurements under harsh conditions (high pressures, temperatures, presence of organic solvents etc.). ${ }^{3,4}$ Conventional sensors are made in the form of planar foils or of fibre-optic setups and are commonly prepared by immobilization of molecular indicators into an oxygen-permeable matrix that acts as a support and solvent for the dye and a permeation-selective membrane. This is also true for nanoparticle-based oxygen probes used in biological and medical research, ${ }^{5}$ but indicators conjugated to proteins ${ }^{6}$ and peptides ${ }^{7,8}$ proved very successful alternatives. The performance of matrix-immobilized sensors is mainly determined by the properties of the indicator (spectral properties, photostability, luminescence decay time) and the matrix (chemical stability, oxygen permeability, permeation selectivity). Compatibility of both materials is important since aggregation of the indicator negatively affects the sensor performance. The sensitivity of optical oxygen sensors is mainly governed by two parameters: luminescence decay time of the indicator and oxygen permeability of the matrix. ${ }^{9}$ Considerably long decay times are required to achieve sufficient sensitivities in common matrices which explains why fluorescent dyes, popular in the early era of oxygen sensor development, ${ }^{1,10}$ are rarely used nowadays. Among numerous phosphorescent indicators explored metalloporphyrins are probably the most popular representatives. ${ }^{10,11}$ Palladium(II) and platinum(II) are almost exclusively used as central atoms; their porphyrin complexes possess phosphorescence lifetimes in order of tens and hundreds of microseconds, respectively. Immobilization of these indicators in polymers with moderate oxygen permeability such as polystyrene and its copolymers with acrylonitrile, poly(methyl methacrylate) etc. results in sensors operating at ambient conditions. On the other hand, highly gas-permeable matrices are required for preparation of sensors for traces of oxygen. These include polymers with high free volume such as silicone rubber, ${ }^{12}$ perfluorinated polymers of Teflon $\mathrm{AF}^{13}$ and $\mathrm{Hyflon}_{\mathrm{AD}}{ }^{14}$ series and poly(1-trimethylsilyl-1-propyne), ${ }^{15}$ which is the polymer with the highest oxygen permeability ever reported. In a different approach, the indicators are physically adsorbed ${ }^{16}$ or covalently ${ }^{13}$ immobilized onto the surface of porous materials such as silica-ge ${ }^{13}$ or mesoporous silica $^{17,18}$ where the dye is fully accessible to the interaction with molecular oxygen.

Another promising way to construct in first sight "matrix-free" indicators is to incorporate the dyes into metal-organic frameworks (MOFs). MOFs are typically crystalline materials that generally consist of metal nodes and organic linkers and are usually characterized by an extremely high porosity. ${ }^{19}$ The great variety of organic linkers and metal nodes enables a huge structural diversity of MOFs, including the synthesis of luminescent variants. ${ }^{20}$ Due to the permanent porosity and high accessibility to gases in the framework, these materials are promising for sensing applications ${ }^{21}$ including oxygen quantification. ${ }^{22}$ The oxygen sensing-unit can be either a structural element of the porous network or, alternatively, be incorporated into the pores during synthesis ${ }^{23}$ or via postsynthetic incubation. ${ }^{24}$ Incorporation into the pores during synthesis does not allow for much control over the distribution of the indicator dye within the framework that is reflected in distinctly nonlinear Stern-Vollmer plots due to different oxygen accessibilities within the crystal. ${ }^{23}$ Additionally, such materials may be prone to leaching of the indicator out of the pores although it can be minimized via design of the pore structure. ${ }^{25}$ On the other hand, incorporation of a sensing element as a MOF building block not only eliminates leaching but also potential aggregation of dyes that may negatively affect the luminescent and sensing properties. Porphyrins are excellent organic linkers for the construction of MOFs and many different frameworks have been described over the last decades. ${ }^{26,27}$ Unfortunately, many of them are prone to hydrolysis ${ }^{28}$ and are therefore of limited interest for sensing applications under ambient conditions. One well-described and hydrolytically considerably stable porphyrin-based MOF is $\mathrm{PCN}-224 .^{29} \mathrm{PCN}-224$ consists of $\mathrm{Zr}_{6}$ clusters which are connected by tetrakis-(4-carboxyphenyl) porphyrin $\left(\mathrm{H}_{2} \mathrm{TCPP}\right)$ as organic linker and is sufficiently insoluble in most common solvents as well as hydrolytically stable in a broad $\mathrm{pH}$ range (1 to 11). This MOF has a permanent porosity with a reported BET surface of $2600 \mathrm{~m}^{2} \mathrm{~g}^{-1}$ and large pore sizes of $1.9 \mathrm{~nm}$ in 
diameter. ${ }^{29}$ These properties renders $\mathrm{PCN}-224$ and closely related MOFs attractive for many applications such as (photo)catalysis, ${ }^{30,31,32}$ photodynamic therapy ${ }^{33,34}$ or drug delivery. ${ }^{26,35,36}$ However, the luminescence properties of the PCN-224 in context of oxygen sensing in the gas phase have not been investigated. Only the Pt(II) derivative of PCN-224, Pt(II)PCN-224, was used for realtime monitoring of dissolved oxygen in aqueous dispersion. The MOF was demonstrated to respond to oxygen in physiologically relevant concentration range showing about 3 -fold quenching of luminescence intensity in air-saturated conditions. ${ }^{37}$ Such sensitivity is comparable to that of the materials prepared by immobilization of $\mathrm{Pt}(\mathrm{II})$ porphyrins in polystyrene or poly(methylmethacrylate) and is much lower than it would be expected from highly porous MOFs. ${ }^{38,39,40}$

In this work we investigate the effect of molecular oxygen on luminescent properties of three MOFs: the fluorescent PCN-224 based on the metal-free porphyrin linker and the phosphorescent analogues $\mathrm{Pt}(\mathrm{II}) \mathrm{PCN}-224$ and $\mathrm{Pd}(\mathrm{II}) \mathrm{PCN}-224$. We will show that the porous framework ensures excellent accessibility of the porphyrin emitters to molecular oxygen and thus unprecedentedly high bimolecular quenching constants. Very efficient quenching in the gas phase is observed already for fluorescent PCN-224 MOF, whereas the luminescence of the metalated analogues is quenched by traces of molecular oxygen. Pd(II)PCN-224 MOF belongs to one of the most oxygen sensitive materials reported so far. In fact, the sensitivity of the Pd(II)PCN-224 MOF exhibiting a SternVolmer constant $\left(\mathrm{K}_{\mathrm{SV}}\right)$ of $2610 \mathrm{kPa}^{-1}$ surpasses by far the sensitivity of known trace oxygen sensors based on $\mathrm{Pd}(\mathrm{II})$ porphyrins immobilized into porous silica-gel matrix $\left(\mathrm{K}_{\mathrm{SV}}\right.$ of $\left.67 \mathrm{kPa}^{-1}\right){ }^{13}$ In this contribution we will also show how the MOFs can be conveniently immobilized onto different materials a step necessary to improve their handling in sensing applications.

\section{Materials and Methods}

\section{Chemicals and Materials}

5,10,15,20-Tetrakis-(4-carboxyphenyl)-21,23H-porphyrin $\left(\mathrm{H}_{2} \mathrm{TCPP}\right)$ was purchased from PorphyrinLaboratories, (Porphyrin-Laboratories GmbH, Gleschendorf, Germany, www.porphyrinlaboratories.com). Zirconyl chloride octahydrate $\left(\mathrm{ZrOCl}_{2} 8 \mathrm{H}_{2} \mathrm{O}\right)$, N,N-dimethylformamide (DMF), acetic acid, potassium chloride and magnesium chloride were obtained from Roth (www.carlroth.com). Magnesium nitrate was acquired from Merck (www.merckmillipore.com). Poly(acrylonitrile) (PAN, $\mathrm{M}_{\mathrm{w}}=150000 \mathrm{~g} / \mathrm{mol}$ ) was from obtained from Sigma Aldrich (www.sigmaaldrich.com). Hyflon ${ }^{\circledR}$ AD 60 was obtained from Solvay (www.solvay.com) and perfluorodecalin was from Fluorochem (www.fluorochem.co.uk). The polyamide (PA) substrate was a Biodyne Plus@Transfer membrane with $0.45 \mu \mathrm{m}$ pore size from Pall (Pall Corporation, Port Washington, USA, www.pall.com). Glass micro-fiber filters (Whatman, $\varnothing 4.7 \mathrm{~cm}$ ) were purchased from Sigma Aldrich (www.sigmaaldrich.com). Silica-gel coated TLC-plates and acetone were from VWR (www.vwr.com). Polyethylene terephthalate (PET) foils $(125 \mu \mathrm{m})$ (MELINEX 506) were supplied by Pütz (Pütz GmbH Co. Folien KG, Taunusstein, Germany; www.puetz-folien.com). Pt(II)TCPP was prepared similar to a previously described procedure ${ }^{41}$ and Pd(II)TCPP was prepared following a previously described microwave-assisted synthesis. ${ }^{42}$ Poly(trimethylsilylpropyne) (PTMSP) was synthesized according to literature. ${ }^{43}$

Synthesis of PCN-224. The synthesis of PCN-224 relies on a published recipe. ${ }^{44}$ In a typical experiment $\mathrm{H}_{2} \mathrm{TCPP}(6.2 \mathrm{mg}, 7.8 \mu \mathrm{mol})$ and $\mathrm{ZrOCl}_{2} \times 8 \mathrm{H}_{2} \mathrm{O}(32.2 \mathrm{mg}, 0.1 \mathrm{mmol})$ were dispersed in a mixture of DMF $(12.5 \mathrm{~mL})$ and acetic acid $(6.2 \mathrm{~mL})$. The dispersion was sonicated for $20 \mathrm{~min}$ in a $50 \mathrm{~mL}$ round bottom flask and kept at $65^{\circ} \mathrm{C}$ for $72 \mathrm{~h}$. After cooling to ambient temperature, the PCN224 crystals were collected by centrifugation and washed three times with DMF $(10 \mathrm{~mL})$ and three times with acetone $(10 \mathrm{~mL})$. For removal of residual DMF, the solid was dispersed in acetone $(3 \mathrm{~mL})$ and volatiles were allowed to evaporate upon heating the dispersion placed on a watch glass on a hotplate operated at $65{ }^{\circ} \mathrm{C}$. This operation was repeated 4 times. Finally, the material was dried under vacuum at $65^{\circ} \mathrm{C}$ until constant weight was reached.

Synthesis of Pt(II)PCN-224 and Pd(II)PCN-224. Pt(II)PCN-224 and Pd(II)PCN-224 were prepared analogously to PCN-224 using Pt(II)TCPP $(7.7 \mathrm{mg}, 7.8 \mu \mathrm{mol})$ or Pd(II)TCPP $(7 \mathrm{mg}, 7.8 \mu \mathrm{mol})$ as 
the starting materials. At the final stage, the crystals were activated for $72 \mathrm{~h}$ in a glass vacuum oven (B-585 from Büchi, www.buchi.com) at 0.7 mbar and $120^{\circ} \mathrm{C}$.

Immobilization of PCN-224. In order to embed PCN-224 into a Hyflon AD 60 layer, a "cocktail" containing $1 \%(\mathrm{w} / \mathrm{w})$ of MOF powder and $10 \%(\mathrm{w} / \mathrm{w})$ Hyflon AD 60 in perflurodecaline was prepared. This composition was knife-coated on PET support (thickness of the wet layer $25 \mu \mathrm{m}$ ) and dried in vacuum overnight.

Immobilization experiments on glass fibres, electrospun PAN nanofibers (see ESI for more details on preparation of electrospun nanofibers), silica-gel TLC substrate and PA filter sheets were done by directly growing the PCN-224 MOF on the substrate. The flat support materials were cut in squares of approximately $10 \times 10 \mathrm{~mm}$ and were immersed in the solution containing MOF precursors and the synthesis was carried out as described above. After the synthesis, residual reactants were removed by soaking the materials in DMF $(10 \mathrm{~mL})$ and acetone $(10 \mathrm{~mL})$. Each solvent was exchanged three times. The materials were dried in vacuum overnight.

Instruments and Methods. Powder X-ray diffraction (PXRD) measurements were performed at the XRD1 beamline at the Elettra Synchrotron in Trieste. This beamline has an operating wavelength of $1.4 \AA$ with a beam size of $200 \times 200 \mu \mathrm{m}$. The data was collected on a stationary Dectris Pilatus $2 \mathrm{M}$ detector which was mounted $400 \mathrm{~mm}$ away from the sample. The sample itself consisted of the MOF PCN-224 powder which was filled in a glass capillary (1.5 mm diameter and $0.02 \mathrm{~mm}$ wall thickness). All data were transformed to reciprocal space for analysis. All data conversion, treatment and analysis steps were performed with GIDVis. ${ }^{45}$

The morphology of the MOF powder samples was studied by a standard scanning electron microscope Jeol JSM-6490 LV (www.jeol.de). For preparing the samples the MOF powder was drop casted onto a Si wafer and carbon coated.

${ }^{1} \mathrm{H}$ NMR spectra were recorded on a $300 \mathrm{MHz}$ Avance III spectrometer from Bruker (www.bruker.com). Absorption spectra were measured on a Varian Cary 50 UV-VIS spectrophotometer from Agilent Technologies (www.agilent.com). Luminescence spectra were recorded on a Fluorolog-3 luminescence spectrometer from Horiba (www.Horiba.com) equipped with a NIR sensitive photomultiplier R2658 from Hamamatsu (www.hamamatsu.com). An optical fiber setup was used to guide the excitation light to a $10 \mathrm{~mL}$ Schlenk flask or a $3 \mathrm{~mL}$ screw-cap glass vial containing the MOF sample and to guide back the emission to the monochromator and photodetector. A custom-made 3D printed adapter (ESI, Fig. S20) was used for fixation of optical fibers. Luminescence decay times were acquired on the same spectrometer equipped with the DeltaHub module. The set-up was similar to the one used in the intensity measurements but a $453 \mathrm{~nm}$ laser diode "NanoLED" from Horiba (www.horiba.com) was used for excitation of PCN-224 and a $405 \mathrm{~nm}$ "SpectraLED" from Horiba (www.horiba.com) for excitation of $\mathrm{Pt}(\mathrm{II}) \mathrm{PCN}-224$ and Pd(II)PCN-224. DAS-6 Analysis software was used for data analysis.

The composition of the calibration gas was adjusted with help of mass-flow controllers from Voegtlin (www.voegtlin.com. Aesch, Switzerland) with the total flow rate of $200 \mathrm{~mL} \mathrm{~min}^{-1}$. For calibration of PCN-224 nitrogen (99.999\% purity) and compressed air were used; for Pt(II)PCN-224 nitrogen of $99.9999 \%$ purity was mixed with the test gas $\left(0.2 \% \mathrm{O}_{2}\right.$ in nitrogen) and for Pd(II)PCN-224 nitrogen of $99.99999 \%$ purity) was mixed with a test gas containing $20 \mathrm{ppm}$ oxygen in nitrogen. All test gases were acquired from Linde gas (www.linde-gas.de). The temperature was $25^{\circ} \mathrm{C}$ in all the experiments. In order to investigate the effect of humidity on the oxygen response of PCN-224, the gas compositions were bubbled through saturated aqueous solutions of $\mathrm{MgCl}_{2}$ (33\% r.h.), $\mathrm{Mg}\left(\mathrm{NO}_{3}\right)_{2}(53$ $\%$ r.h.) and $\mathrm{KCl}(84 \%$ r.h.) before entering the measurement compartment with MOF.

\section{Results and discussion}

\section{Synthesis and structural characterization}

The PCN-224 framework is grown from a solution of $\mathrm{H}_{2}$ TCPP and zirconyl chloride octahydrate in a mixture of DMF and acetic acid. ${ }^{44}$ The MOFs Pt(II)PCN-224 and Pd(II)PCN-224 were synthesized similarly using the $\mathrm{Pt}(\mathrm{II})$ and $\mathrm{Pd}(\mathrm{II})$ metalated porphyrin derivatives of $\mathrm{H}_{2} \mathrm{TCPP}$. Residuals of DMF 
were removed by repeated addition and evaporation of acetone and the MOFs were activated via prolonged treatment in vacuum at elevated temperature $\left(72 \mathrm{~h}, 0.7 \mathrm{mbar}, 120^{\circ} \mathrm{C}\right)$.
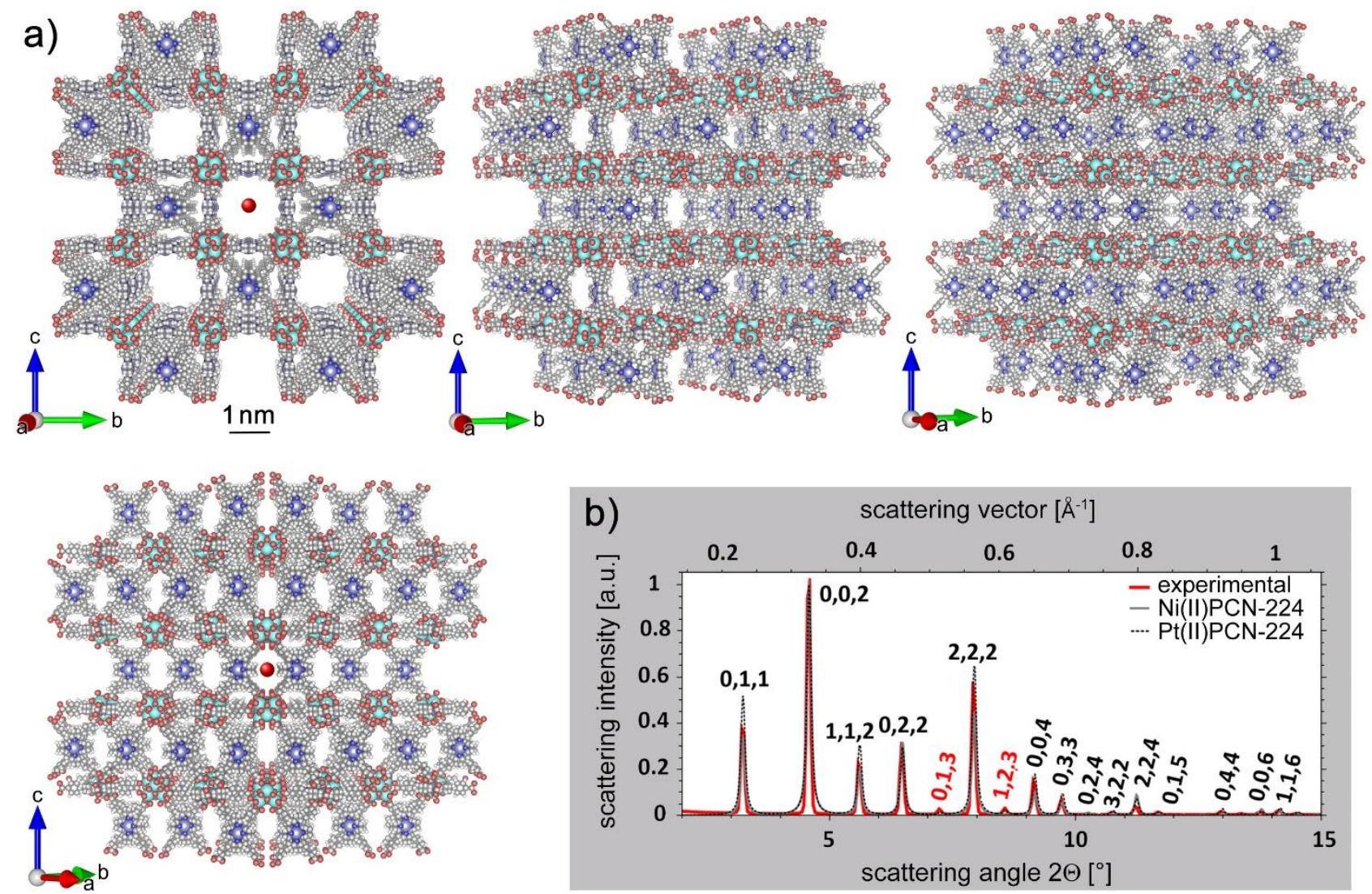

Fig. 1. a) Space fill-model of a metalated PCN-224 drawn in perspective view along the a-axis and rotated for 15, 30 and $45^{\circ}$ around the c-axis showing the channels through the MOF and for comparison a red sphere representing the size of $\mathrm{O}_{2}$ (based on the kinetic diameter of $346 \mathrm{pm}$ ) is shown. The visualization was done with the aid of VESTA. ${ }^{46}$ b) Normalized PXRD data shown as a line graph. Experimental and calculated data for Pt(II)PCN-224 are plotted together with literature data for Ni(II)PCN-224. The data was extracted by integrating over the intensity of the experimental PXRD pattern and normalized to the maximum intensity. The data for the model structures was calculated by using the Mercury software.

The crystal size and morphology of PCN-224, Pt(II)PCN-224 and Pd(II)PCN-224 was investigated using scanning electron microscopy (Fig. S10, S11 and S12, respectively) and cubical crystals with an edge length of around 3-4 $\mu \mathrm{m}$ were obtained in all cases.

Powder X-ray diffraction studies were conducted and the obtained diffractograms were compared to those of PCN-224 and the analogous MOF based on the corresponding Ni(II) complex of TCPP (Ni(II)TCPP).$^{29}$ In both of these reference cases, the structure is cubic and belongs to the space group Im-3m (no. 229). Half of the edges of the $\mathrm{Zr}_{6}$-clusters forming the nodes are bridged by carboxylates from the TCPP ligands and the TCPP linker vacancies appearing in an ordered 3D checkerboard fashion (Fig. 1). To mimic the Pt(II) metalated MOF prepared here, the $\mathrm{Ni}$ (II) in the literature structure was changed for Pt(II). Fig. 1 shows that for both model systems Ni(II)PCN-224 and such a hypothetical $\mathrm{Pt}(\mathrm{II}) \mathrm{PCN}-224$ the relative intensities of all peaks agree well with the relative intensities determined in the experiment. By comparing peak positions and relative intensities between the measured data and the data calculated for the literature structure (Fig. $1 \mathrm{~b}$ for Pt(II)PCN224 and ESI) it is concluded that the synthesized MOF exhibits the same structure as the PCN-224 family reported by Feng et al. ${ }^{29}$ It is to note, that the published structures of PCN-221 (disordered variant of PCN-224) and MOF-525 (all edges of the $\mathrm{Zr}_{6}$ cluster linked with TCPP derivatives) exhibit at scattering angles below $15^{\circ}$ very similar patterns to that of PCN-224. However, only PCN-224 features the superstructure reflections observed at scattering angles of 3.2 and $5.5^{\circ}$ so that the occurrence of ordered vacancies in the crystals discussed here is prevailing. ${ }^{47}$ 


\section{Luminescence of PCN-224 MOFs}

Emission spectra of the three MOFs PCN-224, Pt(II)PCN-224 and Pd(II)PCN-224 are shown in Fig. 2a. In case of PCN-224 the emission is attributed to fluorescence due to decay time in the nanosecond time domain $\left(\tau=6.7 \mathrm{~ns}\right.$ in the absence of $\mathrm{O}_{2}$ ). In contrast, the MOFs based on $\mathrm{Pt}(\mathrm{II})$ and $\mathrm{Pd}(\mathrm{II})$ porphyrins show phosphorescence ( $\tau=18.7$ and $390 \mu \mathrm{s}$, respectively). As can be seen, the emission maximum for the PCN-224 in free powder is located at significantly longer wavelength $(711 \mathrm{~nm})$ than expected and only a small shoulder at around $660 \mathrm{~nm}$ is visible. Such distortion can be attributed to the inner-filter effect that is particularly strong in the MOF due to high concentration of the porphyrin and strong overlap between fluorescence and the $\mathrm{Q}_{\mathrm{x}}(0,0)$ absorption band. The same phenomenon is well known for concentrated solutions of fluorescent emitters including porphyrins. ${ }^{48}$ In accordance to the properties of $\mathrm{Pt}(\mathrm{II})$ and $\mathrm{Pd}(\mathrm{II})$ porphyrins in solutions, the emission maxima of $\mathrm{Pt}(\mathrm{II}) \mathrm{PCN}-224$ is located at shorter wavelength $\left(\lambda_{\max }=645 \mathrm{~nm}\right)$ compared to the corresponding Pd(II) MOF $\left(\lambda_{\max }=675 \mathrm{~nm}\right) .{ }^{49}$ The structure of PCN-224-based MOFs already suggests that individual porphyrin molecules are isolated and their aggregation, which causes pronounced changes of the optical properties ${ }^{49}$ of the materials, is mitigated. Indeed, the excitation spectra recorded for $\mathrm{Pt}(\mathrm{II}) \mathrm{PCN}-224$ (in aqueous dispersion) and the respective building block Pt(II)TCPP (in aqueous solution) are very similar (Fig. 2b). Thus, the arrangement of porphyrin molecules in MOF appears to be an efficient strategy to obtain systems with high concentration of the luminophore without its aggregation.
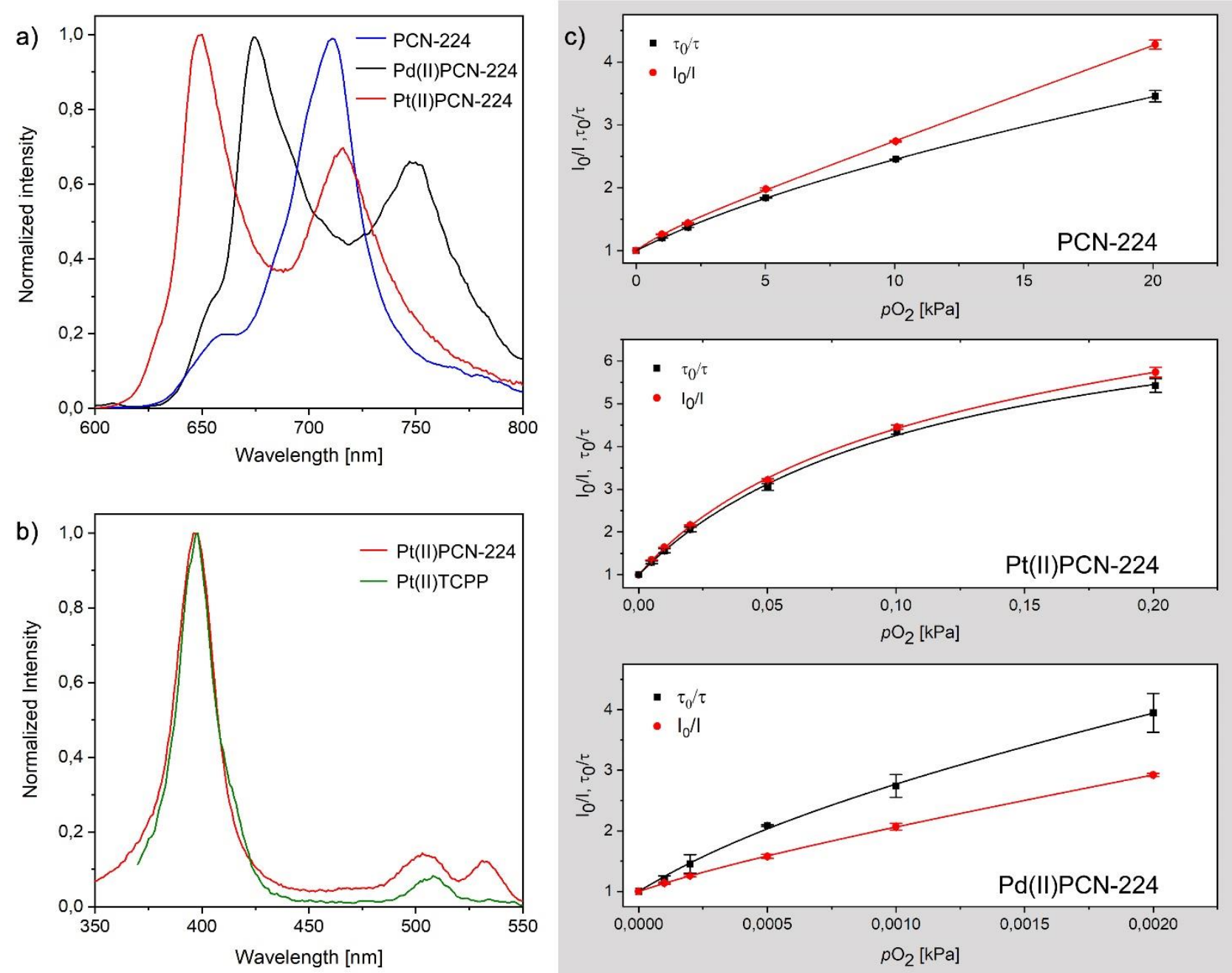

Fig. 2. Luminescence spectra of MOFs; a) emission spectra of PCN-224 ( $\lambda_{\text {exc }} 420 \mathrm{~nm}$ ), Pt(II)PCN-224 ( $\lambda_{\text {exc }}$ $400 \mathrm{~nm})$ and $P d(I I) P C N-224$ ( $\left.\lambda_{e x c} 400 \mathrm{~nm}\right)$ powders under anoxic conditions; b) excitation spectra of Pt(II)TCPP in aqueous solution and Pt(II)PCN-224 in aqueous dispersion ( $\lambda_{e m} 650 \mathrm{~nm}$ ) under anoxic conditions. c) Stern-Volmer plots for PCN-224, Pt(II)PCN-224 and Pd(II)PCN-224 at $25{ }^{\circ} \mathrm{C}$ and dry gas atmosphere. 


\section{Luminescence quenching by molecular oxygen}

Luminescence of the three MOFs was found to be quenched by molecular oxygen (Fig. 2c). Whereas such behaviour was expected for the MOFs based on phosphorescent $\mathrm{Pd}$ (II) and $\mathrm{Pt}(\mathrm{II})$ porphyrins it is very unusual in case of PCN-224 formed by a fluorescent free-base porphyrin. In fact, fluorescent dyes are usually seen as "immune" to oxygen quenching due to their short emission lifetimes. Luminescence quenching by molecular oxygen is of dynamic nature and the Stern-Volmer equation (1) is used to adequately describe the quenching dependency in case of dissolved dyes. In these conditions, the decrease of the luminescence intensity is identical to the decrease of the decay time and both show linear dependency on the concentration of the quencher $\left[\mathrm{O}_{2}\right]$.

$\frac{I_{0}}{I}=\frac{\tau_{0}}{\tau}=1+\mathrm{K}_{\mathrm{SV}} \cdot\left[O_{2}\right]=1+\mathrm{k}_{\mathrm{q}} \cdot \tau_{0} \cdot\left[O_{2}\right]$

where $I_{0}$ and $\tau_{0}$ are the luminescence intensity and luminescence decay time under oxygen-free conditions, I and $\tau$ the same parameters at a certain oxygen concentration, $\mathrm{K}_{\mathrm{SV}}$ is the Stern-Volmer constant and $\mathrm{k}_{\mathrm{q}}$ the bimolecular quenching constant. For indicator dyes immobilized into different matrices (most commonly polymers) such ideal dependency is rarely found. Instead, the dependencies are not linear and not fully identical for the luminescence intensity and the decay time. This is explained by heterogeneity of the environment in which individual indicator molecules are located that results in different oxygen quenchability. As can be seen from Fig. 2c, the same is true for the three MOFs. Such behaviour can be due to combination of several factors including (i) defects in the MOF, (ii) different oxygen accessibility of the porphyrin molecules that are located on the surface of an individual crystal and on the inner pores, (iii) blocking of some pore channels for instance with residual solvent molecules that are trapped inside and hinder oxygen transport. Therefore, the so called "two site model"50 (Eq. 2) was used to fit the experimental data. The model postulates localization of the indicator in two environments of significantly different oxygen permeability and although is physically meaningful only for the luminescence intensity, it also adequately fits the decay time plots.

$\frac{I_{0}}{I}=\left(\frac{f}{1+\mathrm{K}_{\mathrm{SV} 1} \cdot\left[O_{2}\right]}+\frac{1-f}{1+\mathrm{K}_{\mathrm{SV} 2} \cdot\left[O_{2}\right]}\right)^{-1}$

where $f$ is the proportion of the dye localized in the first environment, $\mathrm{K}_{\mathrm{SV} 1}$ and $\mathrm{K}_{\mathrm{SV} 2}$ are the SternVolmer constants for the first and the second environment. Fig. 2c shows that already for PCN-224 based on free-base porphyrin the quenching is very efficient: the fluorescence intensity decreases by more than 4-fold at air saturation comparing to anoxic conditions. For comparison, the quenching of the same magnitude is observed for $\mathrm{Pt}(\mathrm{II})$ porphyrins (such as $\mathrm{Pt}(\mathrm{II}) \mathrm{TFPP}$ ) immobilized in polystyrene. ${ }^{51}$ Notably, the luminescence decay time of Pt(II)TFPP in polystyrene ${ }^{51}$ is roughly 4 orders of magnitude longer $(55 \mu \mathrm{s})$ than that of $\mathrm{H}_{2}$ TCPP in PCN-224 (6.7 ns). Such an efficient quenching in a MOF can be explained by the fact that the porphyrin molecules are structural elements of the porous channels and thus are freely exposed to oxygen molecules that diffuse through them. In contrast, even in polymers with high free-volume polymer chains surround the indicator molecule partly protecting it from interaction with oxygen. It is therefore likely that oxygen permeability in PCN-224 is higher than that of poly(trimethylsilylpropyne) (PTMSP), a polymer with the highest oxygen permeability known. ${ }^{1}$ To verify this, we embedded a lipophilic analogue of $\mathrm{H}_{2} \mathrm{TCPP}$, namely 5,10,15,20-tetrakis-(4-methoxycarbonylphenyl)-21,23H-porphyrin $\left(\mathrm{H}_{2} \mathrm{TMCPP}\right)$ into PTMSP and investigated its oxygen response (Fig. S18). The Stern-Volmer constant obtained for this material is $0.073 \mathrm{kPa}^{-1}$ which is about 3.5-fold lower than for PCN-224 $\left(0.25 \mathrm{kPa}^{-1}\right)$ despite the longer $\tau_{0}$ of $\mathrm{H}_{2}$ TMCPP in PTMSP (10.7 ns).

A known strategy to obtain highly oxygen-sensitive materials is to immobilize the indicator on the surface of a porous material such as silica-gel ${ }^{13}$ or porous aluminium oxide. ${ }^{52}$ In such materials the indicator molecules are exposed to the gas that more or less freely diffuses in the channels. As can be seen, the fluorescence of $\mathrm{H}_{2} \mathrm{TCPP}$ adsorbed on the surface of porous silica-gel is indeed significantly 
quenched by molecular oxygen (Fig. S19). The Stern-Volmer constant of $0.19 \mathrm{kPa}^{-1}$ is however lower that for PCN-224 despite that the fluorescence decay time is higher for $\mathrm{H}_{2} \mathrm{TCPP}$ ( $\tau_{0}$ of $\sim 10 \mathrm{~ns}$ ) than for the porphyrin in the MOF $\left(\tau_{0}=6.7 \mathrm{~ns}\right)$.

Considering the significant quenchability of PCN-224 that relies on a fluorescent dye we expected much stronger sensitivity for phosphorescent Pt(II)PCN-224 and Pd(II)PCN-224. Experimental results (Fig. 2c) show that this is indeed the case. In fact, in case of the former more that 5-fold decrease of luminescence intensity is observed at $0.2 \mathrm{kPa} \mathrm{pO}_{2}$, whereas $\mathrm{Pd}(\mathrm{II}) \mathrm{PCN}-224$ shows 3-fold quenching at only $2 \mathrm{~Pa}$ of oxygen. The limit of detection (LOD) was estimated with the blank value method (blank value +3 x standard deviation). The LOD of Pt(II)PCN-224 was estimated to be $1 \mathrm{~Pa}$ and the LOD of Pd(II)PCN-224 was found to be $0.015 \mathrm{~Pa}$. The materials based on Pt(II) and Pd(II) porphyrins thus cover trace and ultra-trace range of oxygen concentrations. Since the Stern-Volmer constant $\mathrm{K}_{\mathrm{SV}}$ is proportional to the luminescence decay time of the indicator dye (eq. 1), it is interesting to compare the bimolecular quenching constant $\mathrm{k}_{\mathrm{q}}=\mathrm{K}_{\mathrm{Sv}} / \tau_{0}$ that reflects how efficient the diffusion of oxygen in the porous material is. The bimolecular quenching constant $\mathrm{k}_{\mathrm{q}}$ was calculated using the $\mathrm{K}_{\mathrm{Sv}}$ values obtained from the luminescence intensity plots. The $\mathrm{k}_{\mathrm{q}}$ constants were calculated to be 37000,3900 , and $6700 \mathrm{~Pa}^{-1} \mathrm{~s}^{-1}$ for PCN-224, Pt(II)PCN-224 and Pd(II)PCN-224, respectively (Table 1). The bimolecular quenching constant is about one order of magnitude higher for the MOF based on fluorescent free-base porphyrin compared to the phosphorescent MOFs. This is in good agreement with the expectations of $\mathrm{k}_{\mathrm{q}}$ approaching diffusion controlled limit $\left(\mathrm{k}_{\text {diff }}\right)$ for fluorescent dyes (quenching of the excited singlet state) and $1 / 9 \mathrm{k}_{\text {diff }}$ for phosphorescent dyes (quenching of the excited triplet state) due to contribution of the spin-statistical factor. ${ }^{53}$ For comparison, the $\mathrm{k}_{\mathrm{q}}$ constant for $\mathrm{H}_{2}$ TMCPP embedded into PTMSP was calculated to be $7200 \mathrm{~Pa}^{-1} \mathrm{~s}^{-1}$, that is about 5-fold lower than that for PCN-224 indicating that oxygen permeability of the MOF is significantly higher than that of PTMSP. Although the arrangement of the porphyrin molecules in PCN-224 may be particularly advantageous for efficient oxygen quenching, such property is not truly unique and may be characteristic for many other luminescent MOFs. In fact, $\mathrm{k}_{\mathrm{q}}$ constant for the MOF MAFx- $11^{54}$ is $19000 \mathrm{~Pa}^{-1} \mathrm{~s}^{-1}$ which is about 2-fold lower than for PCN-224.

Table 1. Oxygen sensing properties of selected luminescent porous and non-porous materials.

\begin{tabular}{|c|c|c|c|c|c|}
\hline Material & Matrix & $\tau_{0}$ & $\mathrm{~K}_{\mathrm{sv}}\left[\mathrm{kPa}^{-1}\right]$ & $k_{q}\left[\mathrm{~Pa}^{-1} s^{-1}\right]$ & Ref. \\
\hline SUMOF-6-Eu & porous & $1 \mathrm{~ms}$ & 0.07 & 0.07 & 55 \\
\hline EuNDC-MOF & porous & $1.33 \mathrm{~ms}$ & 0.13 & 0.1 & 56 \\
\hline Pt(II)Porph:UiO & porous & $28 \mu \mathrm{s}$ & 0.13 & 4.7 & 57 \\
\hline $\mathrm{Pd}(\mathrm{II}) \mathrm{OEP}$ in PTMSP & polymer & $\sim 770 \mu \mathrm{s}$ & 17 & $\sim 22^{d}$ & 15 \\
\hline $\mathrm{Pt}(\mathrm{II}) \mathrm{BP}$ in silicone rubber & polymer & $50 \mu \mathrm{s}$ & 1.4 & 28 & 12 \\
\hline Pt(II)TFPP in Hyflon AD60 & polymer & $92 \mu \mathrm{s}$ & 3.9 & 42 & 58 \\
\hline $\mathrm{Pd}(\mathrm{II})$ TFPP in Hyflon AD60 & polymer & $1180 \mu \mathrm{s}$ & 62.4 & 53 & 58 \\
\hline Pt(II)TFPP on silica-gel particles & porous & $70 \mu \mathrm{s}$ & 3.7 & 53 & 13 \\
\hline Pt(II)OEP in PTMSP & polymer & $\sim 100 \mu \mathrm{s}$ & 5.6 & $\sim 56^{d}$ & 15 \\
\hline $\mathrm{Pd}(\mathrm{II}) \mathrm{TFPP}$ on silica-gel particles & porous & $987 \mu \mathrm{s}$ & 67 & 68 & 13 \\
\hline $\mathrm{Ru}(\mathrm{II}): \mathrm{MAF}-34$ & porous & $1.18 \mu \mathrm{s}$ & 0.21 & 178 & 23 \\
\hline Pyrene:MAF-4 & porous & $59 \mathrm{~ns}$ & 0.06 & 1000 & 59 \\
\hline $\mathrm{Pt}(\mathrm{II}) \mathrm{PCN}-224$ & porous & $18.6 \mu \mathrm{s}$ & $73^{a}$ & 3900 & This work \\
\hline $\mathrm{Pd}(\mathrm{II}) \mathrm{PCN}-224$ & porous & $390 \mu s^{b}$ & $2610^{a}$ & $6700^{b}$ & This work \\
\hline $\mathrm{H}_{2}$ TMCPP in PTMSP & polymer & $10 \mathrm{~ns}$ & 0.072 & 7200 & This work \\
\hline MAF-X11 & porous & $14 \mathrm{~ns}$ & 0.27 & 19000 & 54 \\
\hline $\mathrm{H}_{2}$ TCPP on silica-gel particles & porous & $10 \mathrm{~ns}$ & 0.19 & 19000 & This work \\
\hline $\mathrm{H}_{2}$ TCPP derivative on $\mathrm{Al}_{2} \mathrm{O}_{3}$ & porous & $\sim 10 \mathrm{~ns}$ & 0.23 & $\sim 23000^{\circ}$ & 52 \\
\hline PCN-224 & porous & $6.7 \mathrm{~ns}$ & $0.25^{a}$ & 37000 & This work \\
\hline
\end{tabular}

${ }^{a}$ Ksv $v_{1}$ fit according to eq. 2. For other fit parameters see Table S3; ${ }^{b}$ Average quenching constant based on bi-exponential decay of two luminescent species; ${ }^{c}$ calculated based on the estimated decay time reported in Ref. 52; ${ }^{d}$ calculated based on the estimated decay times given in Ref. 1

Table 1 summarizes the oxygen-sensing properties of various reported luminescent MOFs as well as selected porous and non-porous materials based on porphyrin indicators embedded in highly 
oxygen-permeable matrices. It should be noted that the selection of materials was limited to those which allowed for the calculation of quenching constant $\mathrm{k}_{\mathrm{q}}$, i.e. contain the data on the luminescence decay time in the absence of the quencher. As can be seen, the bimolecular quenching constant $\mathrm{k}_{\mathrm{q}}$ for most materials is much lower than that obtained for PCN-224, with the exception of MAF-X11 $1^{54}$ and $\mathrm{H}_{2}$ TCPP adsorbed on other porous materials such as silica-gel and aluminium oxide. Comparison of the trace sensors based on $\mathrm{Pt}(\mathrm{II})$ and $\mathrm{Pd}(\mathrm{II})$ porphyrins reveals that these indicators immobilized in porous matrices (silica-gel) and highly oxygen-permeable non-porous polymers (Hyflon AD60, silicone rubber, PTMSP) show the $\mathrm{k}_{\mathrm{q}}$ values in the range of $20-70 \mathrm{~Pa}^{-1} \mathrm{~s}^{-1}$ that is roughly 2 orders of magnitude lower than the bimolecular quenching constant obtained for $\mathrm{Pt}(\mathrm{II}) \mathrm{PCN}-224$ and $\mathrm{Pd}(\mathrm{II}) \mathrm{PCN}-224$. PCN-224 and its metalated analogues thus appear the most oxygen-permeable materials ever reported.

\section{Response times and reversibility}

In a next step, response times and the reversibility were assessed. As shown in Fig. 3 the PCN-224 crystals fully reversibly respond to the alteration between oxygen-free atmosphere and air. The same holds for the two metalated MOF crystals. The dynamic response times $t_{95}$ are within several seconds ( $\sim 6 \mathrm{~s}$ going from anoxic conditions to air and $\sim 7 \mathrm{~s}$ in the reverse direction). Although such response times are comparable to most state-of-the-art oxygen sensors based on polymer-immobilized indicators, they appear to be much longer than expected from extreme oxygen permeability of the MOF. As will be discussed below these values are likely to be greatly overestimated due to the time needed for the gas atmosphere to be exchanged in the chamber with the crystals.
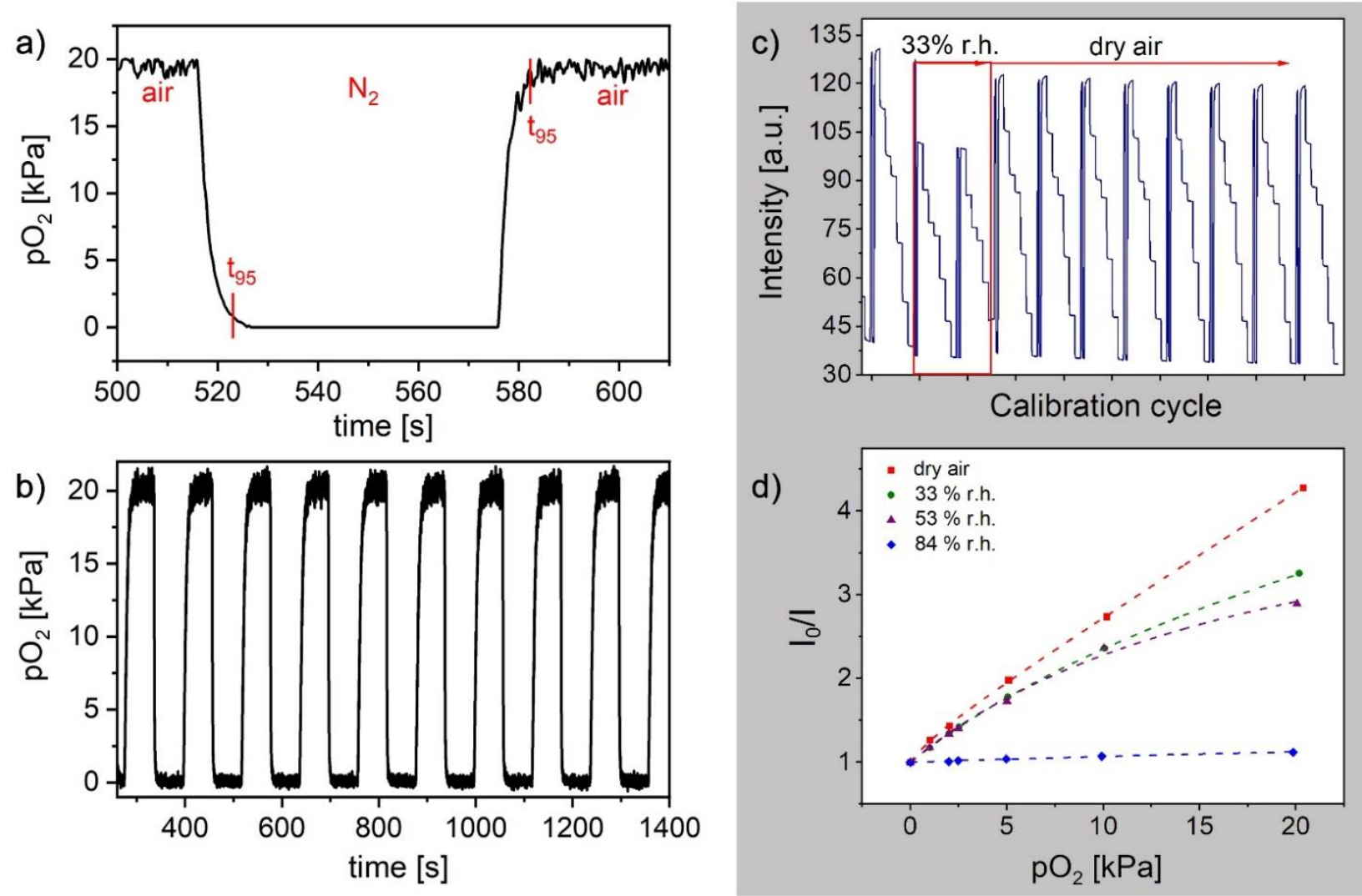

Fig. 3. Oxygen-sensing properties of free-standing PCN-224 crystals; a) dynamic response to alteration of gas atmosphere between nitrogen and air; b) 10 consecutive cycles of changing atmosphere between nitrogen and air demonstrating excellent repeatability and reversibility of the response. Grey box: Influence of humidity on the sensitivity of PCN-224; c) dynamic response of the material in dry air (first and last eight cycles) and at $33 \%$ r.h (cycles 2 and 3); d) Stern-Volmer plots for PCN-224 at varying relative humidity at $25^{\circ} \mathrm{C}$. 


\section{Influence of humidity on oxygen sensitivity}

As was shown in Fig. 2c, $\mathrm{Pt}(\mathrm{II}) \mathrm{PCN}-224$ is extremely sensitive to molecular oxygen in gas phase showing almost 6-fold quenching of phosphorescence intensity already at $0.2 \mathrm{kPa} \mathrm{O}_{2}$. On the other hand, the same material was reposted to show about 3-fold quenching of luminescence intensity in air-saturated aqueous dispersion $\left(\sim 21 \mathrm{kPa} \mathrm{O}_{2}\right) .{ }^{37}$ Such drastic difference in the sensitivity (about 200fold) can be explained by substitution of the gas phase inside the pores of the MOF by aqueous phase. Even for measurement in the gas phase, residual solvents including water can be trapped inside the MOF and thus hinder diffusion of oxygen through the pores. In fact, the extreme oxygen quenching capabilities of MOFs could only be achieved when the materials were fully activated by treatment in vacuum and at elevated temperature $\left(0.7\right.$ mbar, $\left.120{ }^{\circ} \mathrm{C}, 72 \mathrm{~h}\right)$. Fig. $3 \mathrm{c}$ and d shows the humidity influence on the sensing properties of PCN-224. As can be seen, an increase of relative humidity from 0 to $33 \%$ results in some decrease of fluorescence intensity and sensitivity of the material. The behaviour is reversible and the parameters are recovered when dry conditions are established again (Fig. 3c). Increasing relative humidity to 53\% results in further decrease of sensitivity (Fig. 3d), again reversible. However, if the humidity is raised to $84 \%$, a drastic decrease of the sensitivity is observed. Comparison of $\mathrm{K}_{\mathrm{SV}}$ values at 0 and $84 \%$ relative humidity $\left(0.25 \mathrm{kPa}^{-1}\right.$ and $0.008 \mathrm{kPa}^{-1}$, respectively) reveals the decrease of sensitivity by about 30-fold. Notably, this effect cannot be reversed by changing back to dry atmosphere but only by activation of the material at elevated temperature and vacuum. The drastic decrease of sensitivity at high humidity may be due to condensation of water inside of the porous channels of the MOF. In this respect substitution of meso-tetracarboxyphenyl porphyrin with (partly) fluorinated analogues may be a promising way to reduce or even completely overcome the above limitation. Porphyrins bearing fluorine atoms in $\beta$-position are known, ${ }^{60}$ and partial fluorination in the meso-phenyl positions is likely to be feasible.

\section{Immobilization of MOFs}

Potential application of MOFs for optical oxygen sensing requires their immobilization into/onto solid supports to obtain a sensing element with acceptable mechanical stability. A notable exception is the application of MOF (micro)crystals in form of aqueous dispersion. ${ }^{37}$ For all the experiments, PCN-224 was chosen as the model system but results are expected to be applicable to the metalated congeners due to their high structural similarity. A straightforward way to prepare sensing materials is to disperse crystals in a polymeric matrix. To do so, the free crystals (Fig. 4a) were first dispersed in a polymer solution in an organic solvent that was evaporated after film casting. Hyflon AD 60 was chosen for its high oxygen permeability and chemical inertness. ${ }^{61}$ Unfortunately, a drastic loss of sensitivity was observed after immobilization (Fig. 4f).
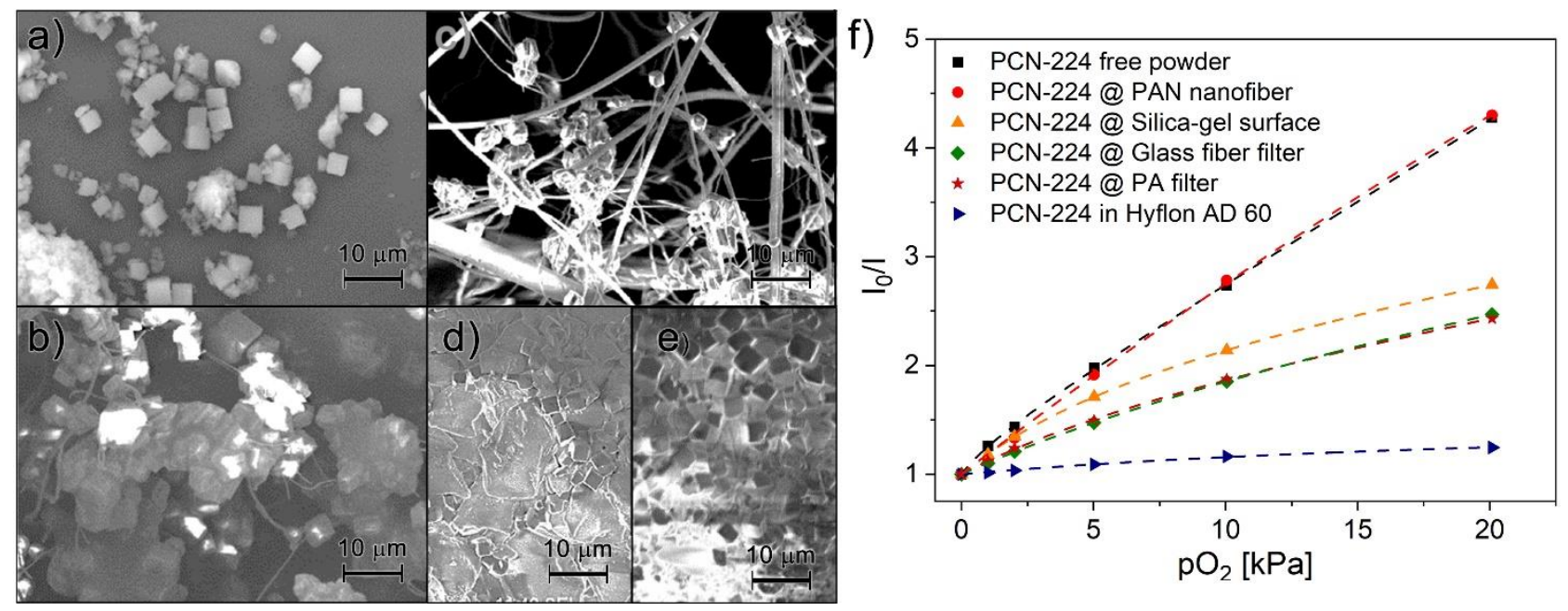

Fig. 4. left: SEM images of the PCN-224 MOF; a) free MOF powder; b) immobilized on electrospun poly(acrylonitrile) nanofibers; c) immobilized on glass fibres of a glass fibre filter; d) crystals grown on silicagel; d) grown on flat PA filter surface. Right; f) Stern-Volmer plots for PCN-224 immobilized onto/in various matrices. 
This may be due to clogging of the pores by flexible polymer chains or entrapped solvent (perfluorodecaline) that hinders oxygen from entering the MOF freely. Notably, perfluorodecaline is much less volatile that water (b.p. $142^{\circ} \mathrm{C}$ ) and is much larger so it may be very difficult to remove it once it gets entrapped in the pores of the MOF. Moreover, removal of residual solvent from the perfluorinated polymer itself was reported to be challenging. ${ }^{62}$

As an alternative approach, the growth of the MOF on different substrates was investigated. ${ }^{63} \mathrm{PCN}-$ 224 was successfully grown on heat-stabilized poly(acrylonitrile) (PAN) nanofibers (Fig. 4b). PAN nanofibers were prepared via an electrospinning technique and a cross-linking step at high temperature $\left(280{ }^{\circ} \mathrm{C}\right)$ that renders the fibres insoluble in DMF. ${ }^{64}$ This property enables the MOF grow from a solution of the precursors in DMF. SEM revealed MOF crystals grown not only on the surface of the fibres but also around the fibres (Fig. S16) and PXRD confirmed the structure of PCN-224 grown on the fibrous support (Fig. S17). The oxygen sensitivity of the obtained material is very similar to that of the individual crystals (Fig. 4f). This is not the case for several other composite materials. MOF crystals grown on different Si-based materials such as a glass fibre filter (Fig. 4c, Fig. S13) and aluminium-supported silica-gel (Fig. 4d, Fig. S15) exhibited some decrease of oxygen sensitivity (Fig. 4f). The decrease in sensitivity may be due to blocking of some part of the crystals by the virtually oxygen-impermeable glass/silica-gel backbone. PCN-224 was also grown on a flat polyamide (PA) filter (Fig. 6e, Fig. S14) and a similar decrease in the sensitivity was observed (Fig. 4f). For the flat silica-gel and PA supports the individual crystals are comparable in size and the oxygen sensitivity is also very similar.
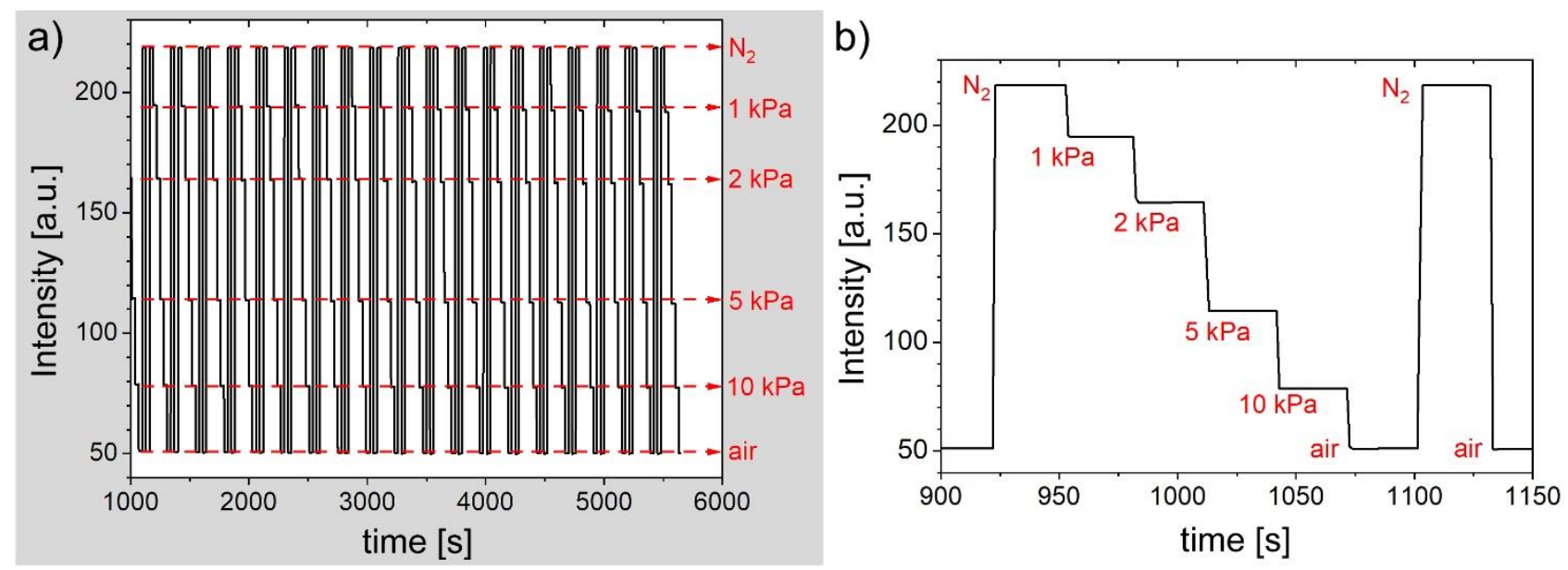

Fig. 5. a) Fluorescence intensity response of PCN-224 grown on PAN nanofibers to alteration of oxygen content in the gas atmosphere during 19 consecutive calibration cycles; b) Dynamic response of PCN-224 grown on PAN nanofibers.

Finally, the sensing properties of PCN-224 grown on PAN nanofibers were investigated in more detail. The response of the material is very fast and fully reversible (Fig. 5a) and is generally similar to that of the free crystals. It should be noted that since the compact PCN-224 crystals are grown around the individual PAN fibres, their position in the sensor material is fixed and there is no possibility of movement of individual crystals anymore. This allows for a very fast exchange of the gas atmosphere so that the measured response times are closer to the true values (in particular when compared to the measurement performed with the free crystals presented in Fig. 4). The full response $\left(\mathrm{t}_{100}\right)$ in both directions was accomplished within 1s (Fig. 5b), which again appears to reflect the time needed for the gas exchange. The true response times in terms of more commonly used t95 (time needed for $95 \%$ of the signal change) are expected to be well below $1 \mathrm{~s}$. During 19 consecutive calibration cycles, almost no drift (less than $2 \%$ over a continuous illumination of more than one hour and 19 consecutive cycles) was found and no change in sensing behaviour was observed. Therefore, immobilization by growing PCN-224-related materials on PAN nanofibers can be considered highly promising for preparation of solid state (sensing) materials. 


\section{Conclusions}

Porous MOFs prepared from luminescent porphyrins as building blocks show extremely interesting oxygen sensing properties in gas phase. Compared to conventional oxygen-sensing materials it becomes possible to suppress aggregation of dye molecules and achieve high indicator content in the sensing material. High porosity and "free-standing" dye molecules are responsible for unprecedentedly efficient quenching of the luminescence by molecular oxygen. Significant quenching is observed already for the MOF based on a fluorescent porphyrin dye despite its short fluorescence decay time of several nanoseconds. Phosphorescence of MOFs that make use of analogous $\mathrm{Pt}(\mathrm{II})$ and $\mathrm{Pd}(\mathrm{II})$ porphyrins is quenched by trace amounts of oxygen. The bimolecular quenching constant $\mathrm{k}_{\mathrm{q}}$ is extremely high and exceeds by several folds the value obtained for the porphyrins immobilized in poly(trimethylsilylpropyne), a polymer with the highest oxygen permeability known. MOF growth on porous support materials paves the way for their practical applications in oxygen sensing in gas phase. Among several materials investigated, cross-linked poly(acrylonitrile) nanofibers were found to be particularly promising, since the oxygen-sensing characteristics are virtually the same as for the free crystals. The material shows fast and fully reversible response. A current limitation of the PCN-224 based MOFs in oxygen sensing is the crosstalk to humidity and the drastic decrease of the sensitivity at high humidity. Substitution of the dye molecules used as building blocks by fluorinated porphyrins may help to overcome the current limitation.

\section{Conflict of interest}

The authors have no conflict of interest to declare

\section{Acknowledgements}

The work was financially supported by the lead-project LP-03 Porous Materials at Work at Graz University of Technology. The authors would like to thank Luisa Barba, beamline scientist at the Elettra synchrotron in Trieste (beamline XRD1), for her support and Roland Resel for discussion.

\section{Supporting Information}

The supporting information contains preparations of the precursors, a detailed description of the PXRD experiments and results, SEM images of free crystals and additional SEM images of the immobilized MOFs, PXRD data for PCN-224 grown on PAN-fibres, fit parameters for the SternVolmer plots obtained for different samples of PCN-224-based MOFs and Stern-Volmer plots of reference measurements.

\section{References}

1 X. Wang and O. S. Wolfbeis, Optical methods for sensing and imaging oxygen: materials, spectroscopies and applications, Chem. Soc. Rev., 2014, 43, 3666-3761. DOI: 10.1039/C4CS00039K

2 P. Lehner, C. Staudinger, S. M. Borisov and I. Klimant, Ultra-sensitive optical oxygen sensors for characterization of nearly anoxic systems, Nat. Commun., 2014, 5, 1-6. DOI: 10.1038/ncomms5460

3 P. Sulzer, R. Lebl, C. O. Kappe and T. Mayr, Oxygen sensors for flow reactors - measuring dissolved oxygen in organic solvents, React. Chem. Eng., 2019, 4, 2081-2087. DOI: 10.1039/C9RE00253G

4 M. Tservistas, R. Koneke, A. Comte and T. Scheper, Oxygen monitoring in supercritical carbon dioxide using a fibre optic sensor, Enzyme Microb. Technol., 2001, 28, 637-641. DOI: 10.1016/S0141-0229(01)00317-9

5 X. Wang, J. A. Stolwijk, T. Lang, M. Sperber, R. J. Meier, J. Wegener and O. S. Wolfbeis, Ultra-Small, Highly Stable, and Sensitive Dual Nanosensors for Imaging Intracellular Oxygen and pH in Cytosol, J. Am. Chem. Soc., 2012, 134, 17011-17014. DOI: 10.1021/ja308830e

6 J. Hynes, S. Floyd, A. E. Soini, R. O’Connor and D. B. Papkovsky, Fluorescence-Based Cell Viability Screening Assays Using Water-Soluble Oxygen Probes, J. Biomol. Screen., 2003, 8, 264-272. DOI: 10.1177/1087057103008003004

7 R. I. Dmitriev, A. V. Zhdanov, G. V. Ponomarev, D. V. Yashunski and D. B. Papkovsky, Intracellular oxygensensitive phosphorescent probes based on cell-penetrating peptides, Anal. Biochem., 2010, 398, 24-33. DOI: 10.1016/j.ab.2009.10.048 
8 K. Koren, R. I. Dmitriev, S. M. Borisov, D. B. Papkovsky and I. Klimant, Complexes of IIIII-

Octaethylporphyrin with Peptides as Probes for Sensing Cellular $\mathrm{O}_{2}$, ChemBioChem, 2012, 13, 1184-1190. DOI: $10.1002 /$ cbic. 201200083

9 A. Mills, Controlling the sensitivity of optical oxygen sensors, Sens. Actuat. B Chem., 1998, 51, 60-68. DOI: 10.1016/S0925-4005(98)00211-1

10 M. Quaranta, S. M. Borisov and I. Klimant, Indicators for optical oxygen sensors, Bioanal. Rev., 2012, 4, 115157. DOI: $10.1007 / \mathrm{s} 12566-012-0032-\mathrm{y}$

11 H. Lee, K.-I. Hong and W.-D. Jang, Design and applications of molecular probes containing porphyrin derivatives, Coord. Chem. Rev., 2018, 354, 46-73. DOI: 10.1016/j.ccr.2017.06.008

12 B. J. Müller, T. Burger, S. M. Borisov and I. Klimant, High performance optical trace oxygen sensors based on NIR-emitting benzoporphyrins covalently coupled to silicone matrixes, Sens. Actuat. B Chem., 2015, 216, 527-534. DOI: 10.1016/j.snb.2015.04.067

13 S. M. Borisov, P. Lehner and I. Klimant, Novel optical trace oxygen sensors based on platinum(II) and palladium(II) complexes with 5,10,15,20-meso-tetrakis-(2,3,4,5,6-pentafluorphenyl)-porphyrin covalently immobilized on silica-gel particles, Anal. Chim. Acta, 2011, 690, 108-115. DOI: 10.1016/j.aca.2011.01.057

14 P. Lehner, C. Larndorfer, E. Garcia-Robledo, M. Larsen, S. M. Borisov, N.-P. Revsbech, R. N. Glud, D. E. Canfield and I. Klimant, LUMOS - A Sensitive and Reliable Optode System for Measuring Dissolved Oxygen in the Nanomolar Range, PLoS One, 2015, 10, e0128125. DOI: 10.1371/journal.pone.0128125

15 Y. Amao, K. Asai, I. Okura, H. Shinohara and H. Nishide, Platinum porphyrin embedded in poly(1trimethylsilyl-1-propyne) film as an optical sensor for trace analysis of oxygen, Analyst, 2000, 125, 19111914. DOI: $10.1039 / \mathrm{B} 005838 \mathrm{~F}$

16 B.-H. Han, I. Manners and M. A. Winnik, Phosphorescence Quenching of Dyes Adsorbed to Silica Thin-Layer Chromatography Plates, Chem. Mater., 2005, 17, 3160-3171. DOI: 10.1021/ac0511703

17 H. Zhang, Y. Sun, K. Ye, P. Zhang and Y. Wang, Oxygen sensing materials based on mesoporous silica MCM-41 and Pt(ii)-porphyrin complexes, J. Mater. Chem., 2005, 15, 3181-3186. DOI: 10.1039/B503336E

18 B. Wang, L. Zhang, B. Li, Y. Li, Y. Shi and T. Shi, Synthesis, characterization, and oxygen sensing properties of functionalized mesoporous silica SBA-15 and MCM-41 with a Pt(II)-porphyrin complex, Sens. Actuat. B Chem., 2014, 190, 93-100. DOI: 10.1016/j.snb.2013.08.036

19 H.-C. Zhou, J. R. Long and O. M. Yaghi, Introduction to Metal-Organic Frameworks, Chem. Rev. 2012, 112, 673-674. DOI: $10.1021 / \mathrm{cr} 300014 \mathrm{x}$

20 Y. Cui, Y. Yue, G. Qian and B. Chen, Luminescent Functional Metal-Organic Frameworks, Chem. Rev., 2012, 112, 1126-1162. DOI: $10.1021 / \mathrm{cr} 200101 \mathrm{~d}$

21 L. E. Kreno, K. Leong, O. K. Farha, M. Allendorf,, R. P. Van Duyne and J. T. Hupp, Metal-Organic Framework Materials as Chemical Sensors, Chem. Rev. 2012, 112, 1105-1125. DOI: 10.1021/cr200324t

22 P. Kumar, A. Deep and K.-H. Kim, Metal organic frameworks for sensing applications, Trends Analyt. Chem., 2015, 73, 39-53. DOI: 10.1016/j.trac.2015.04.009

23 X.-L. Qi, S.-Y. Liu, R.-B. Lin, P.-Q. Liao, J.-W. Ye, Z. Lai, Y. Guan, X.-N. Cheng, J.-P. Zhang and X.-M. Chen, Phosphorescence doping in a flexible ultramicroporous framework for high and tunable oxygen sensing efficiency, Chem. Commun., 2013, 49, 6864-6866. DOI: 10.1039/C3CC43461C

24 Z. Dou, J. Yu, Y. Cui, Y. Yang, Z. Wang, D. Yang and G. Qian, Luminescent Metal-Organic Framework Films As Highly Sensitive and Fast-Response Oxygen Sensors, J. Am. Chem. Soc., 2014, 136, 5527-5530. DOI: $10.1021 / j a 411224 j$

25 J. Juan-Alcañiz, J. Gascon and F. Kapteijn, Metal-organic frameworks as scaffolds for the encapsulation of active species: state of the art and future perspectives, J. Mater. Chem., 2012, 22, 10102-10118. DOI: 10.1039/C2JM15563J

26 X. Zhang, M. C. Wasson, M. Shayan, E. K. Berdichevsky, J. Ricardo-Noordberg, Z. Singh, E. K. Papazyan, A. J. Castro, P. Marino, Z. Ajoyan, Z. Chen, T. Islamoglu, A. J. Howarth, Y. Liu, M. B. Majewski, M. J. Katz, J. E. Mondloch, O. K. Farha, A historical perspective on porphyrin-based metal-organic frameworks and their applications, Coord. Chem. Rev., 2021, 429, 213615. DOI: 10.1016/j.ccr.2020.213615

27 S. S. Rajasree, X. Li, and P. Deria, Physical properties of porphyrin-based crystalline metal-organic frameworks, Commun. Chem. 2021, 4, 47. DOI: 10.1038/s42004-021-00484-4

28 S. Yuan, L. Feng, K. Wang, J. Pang, M. Bosch, C. Lollar, Y. Sun, J. Qin, X. Yang, P. Zhang, Q. Wang, L. Zou, Y. Zhang, L. Zhang, Y. Fang, J. Li and H.-C. Zhou, Stable Metal-Organic Frameworks: Design, Synthesis, and Applications, Adv. Mater., 2018, 30, 1704303. DOI: 10.1002/adma.201704303 
29 D. Feng, W.-C. Chung, Z. Wei, Z.-Y. Gu, H. L. Jiang, Y.-P. Chen, D. J. Darensbourg and H.-C. Zhou, Construction of Ultrastable Porphyrin Zr Metal-Organic Frameworks through Linker Elimination, J. Am. Chem. Soc., 2013, 135, 17105-17110. DOI: 10.1021/ja408084j

30 N. Huang, S. Yuan, H. Drake, X. Yang, J. Pang, J. Qin, J. Li, Y. Zhang, Q. Wang, D. Jiang and H.-C. Zhou, Systematic Engineering of Single Substitution in Zirconium Metal-Organic Frameworks toward HighPerformance Catalysis, J. Am. Chem. Soc., 2017, 139, 18590-18597. DOI: 10.1021/jacs.7b09553

31 X. Liu, W. Qi, Y. Wang, D. Lin, X. Yang, R. Su and Z. He, Rational Design of Mimic Multienzyme Systems in Hierarchically Porous Biomimetic Metal-Organic Frameworks, ACS Appl. Mater. Interfaces, 2018, 10, 33407-33415. DOI: 10.1021/acsami.8b09388

32 L. Feng, K.-Y. Wang, E. Joseph and H.-C. Zhou, Catalytic Porphyrin Framework Compounds, Trends Chem., 2020, 2, 555-568. DOI: 10.1016/j.trechm.2020.01.003

33 J. Park, Q. Jiang, D. Feng, L. Mao and H.-C. Zhou, Size-Controlled Synthesis of Porphyrinic Metal-Organic Framework and Functionalization for Targeted Photodynamic Therapy, J. Am. Chem. Soc., 2016, 138, 35183525. DOI: $10.1021 /$ jacs.6b00007

34 A. Schlachter, P. Asselin and P. D. Harvey, Porphyrin-Containing MOFs and COFs as Heterogeneous Photosensitizers for Singlet Oxygen-Based Antimicrobial Nanodevices, ACS Appl. Mater. Interfaces, 2021, 13, 26651-26672. DOI: 10.1021/acsami.1c05234

35 J. Chen, Y. Zhu and S. Kaskel, Porphyrin-Based Metal-Organic Frameworks for Biomedical Applications, Angew. Chem. Int. Ed., 2021, 60, 5010-5035. DOI: 10.1002/anie.201909880

36 J. Wang, Y. Fan, Y. Tan, X. Zhao, Y. Zhang, C. Cheng and M. Yang, Porphyrinic Metal-Organic Framework PCN-224 Nanoparticles for Near-Infrared-Induced Attenuation of Aggregation and Neurotoxicity of Alzheimer's Amyloid- $\beta$ Peptide, ACS Appl. Mater. Interfaces, 2018, 10, 36615-36621. DOI: 10.1021/acsami.8b15452

37 J. Yang, Z. Wang, Y. Li, Q. Zhuang and J. Gu, Real-Time Monitoring of Dissolved Oxygen with Inherent Oxygen-Sensitive Centers in Metal-Organic Frameworks, Chem. Mater., 2016, 28, 2652-2658. DOI: $\underline{10.1021 / \text { acs.chemmater.6b00016 }}$

38 S. M. Barrett, C. Wang and W. Lin, Oxygen sensing via phosphorescence quenching of doped metal-organic frameworks, J. Mater. Chem., 2012, 22, 10329-10334. DOI: 10.1039/C2JM15549D

39 C.-Y. Zhu, Z. Wang, J.-T. Mo, Y.-N. Fan and M. Pan, A long persistent phosphorescent metal-organic framework for multi-level sensing of oxygen, J. Mater. Chem. C, 2020, 8, 9916-9922. DOI: 10.1039/D0TC02391D

40 G. Lan, K. Ni, E. You, M. Wang, A. Culbert, X. Jiang and W. Lin, Multifunctional Nanoscale Metal-Organic Layers for Ratiometric pH and Oxygen Sensing, J. Am. Chem. Soc., 2019, 141, 18964-18969. DOI: 10.1021/jacs.9b11024

41 S.-Y. Li, B.-R. Xie, H. Cheng, C.-X. Li, M.-K. Zhang, W.-X. Qiu, W.-L. Liu, X.-S. Wang and X.-Z. Zhang, A biomimetic theranostic $\mathrm{O}_{2}$-meter for cancer targeted photodynamic therapy and phosphorescence imaging, Biomaterials, 2018, 151, 1-12. DOI: 10.1016/j.biomaterials.2017.10.021

42 M. L. Dean, J. R. Schmink, N. E. Leadbeater and C. Brückner, Microwave-promoted insertion of Group 10 metals into free base porphyrins and chlorins: scope and limitations, Dalton Trans., 2008, 1341. DOI: $\underline{10.1039 / \mathrm{B} 716181 \mathrm{~F}}$

43 M. Langsam, M. Anand and E. J. Karwacki, Substituted propyne polymers: I. Chemical surface modification of poly[1-(trimethylsilyl] propyne] for gas separation membranes, Gas Sep. Purif., 1988, 2, 162-170, DOI: 10.1016/0950-4214(88)80001-X

44 J. Yang, Z. Wang, Y. Li, Q. Zhuang, W. Zhao and J. Gu, Porphyrinic MOFs for reversible fluorescent and colorimetric sensing of mercury(ii) ions in aqueous phase, RSC Adv., 2016, 6, 69807-69814. DOI: 10.1039/C6RA13766K

45 B. Schrode, S. Pachmajer, M. Dohr, C. Röthel, J. Domke, T. Fritz, R. Resel and O. Werzer, GIDVis: a comprehensive software tool for geometry-independent grazing-incidence X-ray diffraction data analysis and pole-figure calculations, J. Appl. Crystallogr., 2019, 52, 683-689. DOI: 10.1107/S1600576719004485

$46 \mathrm{~K}$. Momma and F. Izumi, VESTA 3 for three-dimensional visualization of crystal, volumetric and morphology data. J. Appl. Crystallogr., 2011, 44, 1272-1276. DOI: 10.1107/S0021889811038970

47 C. Koschnick, R. Stäglich, T. Scholz, M. W. Terban, A. von Mankowski, G. Savasci, F. Binder, A. Schökel. M. Etter, J. Nuss, R. Siegel, L. S. Germann, C. Ochsenfeld, R. E. Dinnebier, J. Senker and B. V. Lotsch, Understanding disorder and linker deficiency in porphyrinic zirconium-based metal-organic frameworks by resolving the $\mathrm{Zr}_{8} \mathrm{O}_{6}$ cluster conundrum in PCN-221, Nat. Commun., 2021, 12, 3099. DOI: 10.1038/s41467$\underline{021-23348-\mathrm{W}}$ 
48 M. Ghosh, S. Nath, A. Hajra and S. Sinha, Fluorescence self-quenching of tetraphenylporphyrin in liquid medium, J. Lumin., 2013, 141, 87-92. DOI: 10.1016/j.jlumin.2013.03.025

49 V. V. Vasil'ev, S. M. Borisov, Yu. O. Chubarova and V. D. Rumyantseva, Dimerization, Aggregation, and Luminescent Properties of Palladium(II) and Platinum(II) Complexes with meso-Tetrakis(4carboxyphenyl)porphyrin, Russ. J. Inorg. Chem., 2003, 48, 385-390.

50 E. R. Carraway, J. N. Demas, B. A. DeGraff and J. R. Bacon, Photophysics and photochemistry of oxygen sensors based on luminescent transition-metal complexes, Anal. Chem., 1991, 63, 337-342. DOI: 10.1021/ac00004a007

51 S. M. Borisov and I. Klimant, Ultrabright Oxygen Optodes Based on Cyclometalated Iridium(III) Coumarin Complexes, Anal. Chem., 2007, 79, 7501-7509. DOI: 10.1021/ac0710836

52 N. Araki, Y. Amao, T. Funabiki, M. Kamitakahara, C. Ohtsuki, K. Mitsuo, K. Asai, M. Obata and S. Yano, Optical oxygen-sensing properties of porphyrin derivatives anchored on ordered porous aluminium oxide plates, Photochem. Photobiol. Sci., 2007, 6, 794-803. DOI: 10.1039/B618030B

53 Schweitzer and R. Schmidt, Physical Mechanisms of Generation and Deactivation of Singlet Oxygen, Chem. Rev., 2003, 103, 1685-1758. DOI: 10.1021/cr010371d

54 R.-B. Lin, F. Li, S.-Y. Liu, X.-L. Qi, J.-P. Zhang and X.-M. Chen, A Noble-Metal-Free Porous Coordination Framework with Exceptional Sensing Efficiency for Oxygen, Angew. Chem., Int. Ed., 2013, 52, 13429-13433. DOI: 10.1002/anie.201307217

55 X.-Y. Xu and Bing. Yan, Nanoscale LnMOF-functionalized nonwoven fibers protected by a polydimethylsiloxane coating layer as a highly sensitive ratiometric oxygen sensor, J. Mater. Chem. C, 2016, 4, 8514-8521. DOI: $10.1039 /$ C6TC02569B

56 T. Xia, L. Jiang, J. Zhang, Y. Wan, Y. Yang, J. Gan, Y. Cui, Z. Yang and G. Qian, A fluorometric metalorganic framework oxygen sensor: from sensitive powder to portable optical fiber device, Microporous Mesoporous Mater., 2020, 305, 110396. DOI: 10.1016/j.micromeso.2020.110396

57 R. Xu, Y. Wang, X. Duan, K. Lu, D. Micheroni, A. Hu and Wenbin. Lin, Nanoscale Metal-Organic Frameworks for Ratiometric Oxygen Sensing in Live Cells, J. Am. Chem. Soc., 2016, 138, 2158-2161. DOI: 10.1021/jacs.5b13458

58 M. Larsen, P. Lehner, S. M. Borisov, I. Klimant, J. P. Fischer, F. J. Stewart, D. E. Canfield and R. N. Glud, In situ quantification of ultra-low $\mathrm{O} 2$ concentrations in oxygen minimum zones: Application of novel optodes, Limnol. Oceanogr. Methods, 2016, 14, 784-800. DOI: 10.1002/lom3.10126

59 J.-W. Ye, H.-L. Zhou, S.-Y. Liu, X.-N. Cheng, R.-B. Lin, X.-L. Qi, J.-P. Zhang and X.-M. Chen, Encapsulating Pyrene in a Metal-Organic Zeolite for Optical Sensing of Molecular Oxygen, Chem. Mater., 2015, 27, 8255-8260. DOI: 10.1021/acs.chemmater.5b03955

60 S.-W. Lai, Y.-J. Hou, C.-M. Che, H.-L. Pang, K.-Y. Wong, C. K. Chang and N. Zhu, Electronic Spectroscopy, Photophysical Properties, and Emission Quenching Studies of an Oxidatively Robust Perfluorinated Platinum Porphyrin, Inorg. Chem., 2004, 43, 3724-3732. DOI: 10.1021/ic049902h

61 V. Arcella, A. Ghielmi and G. Tommasi, High Performance Perfluoropolymer Films and Membranes, Ann. N. Y. Acad. Sci., 2003, 984, 226-244. DOI: 10.1111/j.1749-6632.2003.tb06002.x

62 J. C. Jansen, M. Macchione and E. Drioli, On the unusual solvent retention and the effect on the gas transport in perfluorinated Hyflon AD® membranes, J. Membr. Sci., 2007, 287, 132-137. DOI: 10.1016/j.memsci.2006.10.031

63 Y. Zhang, S. Yuan, X. Feng, H. Li, J. Zhou and B. Wang, Preparation of Nanofibrous Metal-Organic Framework Filters for Efficient Air Pollution Control, J. Am. Chem. Soc., 2016, 138, 5785-5788. DOI: 10.1021/jacs.6b02553

64 M. Wu, Q. Wang, K. Li, Y. Wu and H. Liu, Optimization of stabilization conditions for electrospun polyacrylonitrile nanofibers, Polym. Degr. Stab., 2012, 97, 1511-1519. DOI: $\underline{10.1016 / j . p o l y m d e g r a d s t a b .2012 .05 .001}$ 